\title{
Isabelle RENAUD-CHAMSKA (éd.), Paris et ses églises de la Belle époque à nos jours
}

Paris, Picard, 2017, 416 p.

\section{Alain Rauwel}

\section{CpenEdition} Journals

Édition électronique

URL : https://journals.openedition.org/assr/45143

DOI : $10.4000 /$ assr.45143

ISSN : 1777-5825

Éditeur

Éditions de l'EHESS

Édition imprimée

Date de publication : 1 décembre 2018

Pagination : 354-356

ISSN : 0335-5985

\section{Référence électronique}

Alain Rauwel, «Isabelle RENAUD-CHAmSKA (éd.), Paris et ses églises de la Belle époque à nos jours », Archives de sciences sociales des religions [En ligne], 184 | octobre-décembre 2018, mis en ligne le 01 décembre 2018, consulté le 16 janvier 2022. URL : http://journals.openedition.org/assr/45143; DOI : https://doi.org/10.4000/assr.45143

Ce document a été généré automatiquement le 16 janvier 2022.

(c) Archives de sciences sociales des religions 


\title{
Isabelle RENAUD-CHAMSKA (éd.), Paris et ses églises de la Belle époque à nos jours
}

Paris, Picard, 2017, 416 p.

\author{
Alain Rauwel
}

\section{RÉFÉRENCE}

Isabelle RENAUD-CHAMSKA (éd.), Paris et ses églises de la Belle époque à nos jours, Paris, Picard, 2017, 416 p.

1 L'église dit l'Église : les chercheurs en sciences sociales du religieux sont désormais familiers de cet axiome qui rend compte de l'effet de métonymie entre le bâtiment cultuel et la communauté croyante et ouvre toute grande la voie des travaux sur la spatialisation du sacré. Ce qui est attesté depuis les premiers sanctuaires chrétiens prend plus de poids encore au $\mathrm{xx}^{\mathrm{e}}$ siècle, tant il est vrai que jamais dans l'histoire l'ecclésiologie n'a changé si fondamentalement et si rapidement, suscitant une évolution de même rythme dans la construction et le décor des églises. Pour en prendre la pleine mesure, il convient de choisir un terrain où les circonstances aient favorisé une activité architecturale intense ; un grand diocèse urbain fournira donc plus ample matière qu'un diocèse rural - et parmi les métropoles, quel cas plus riche que Paris ? Une capitale en plein essor depuis la Révolution industrielle, étendant continuellement son territoire et sa population, exigeant toujours plus de lieux de culte pour les paroisses nouvelles ou agrandies, avec en outre des moyens suffisants pour mobiliser matériaux nobles et compétences reconnues : voilà un cas d'étude idéal. On se réjouit donc vivement que l'excellente maison Picard, lançant sous la direction de Mathieu Lours une collection encyclopédique sur «Paris et ses églises", publie un magnifique ouvrage présentant et recensant les églises contemporaines de la ville (la ville seulement, sans sa banlieue, puisque le volume s'en tient aux limites du diocèse rétréci 
de 1966, ce qui en l'espèce n'est pas un inconvénient puisque les éditions du Patrimoine avaient donné dès 2002 un remarquable Des sanctuaires hors les murs).

2 Le sujet est largement neuf. Des études ponctuelles existent, mais la grande synthèse ici offerte est pionnière. Luc Perrin (non cité dans la bibliographie finale) avait abordé la question dans sa thèse sur Paris à l'heure de Vatican II, et Paul Airiau, toujours curieux, avait jeté un premier coup de sonde dans les archives de la Commission diocésaine d'Art sacré (pour le colloque de 2006, Les lieux de culte en France, ignoré aussi de la bibliographie). L'entreprise des éditions Picard est bien plus ambitieuse : plus de 150 pages initiales pour fixer le cadre matériel, artistique et religieux, dans lesquelles on retient surtout la réflexion d'I. Renaud-Chamska sur «Architecture et liturgie au $\mathrm{xx}^{\mathrm{e}}$ siècle dans les églises de Paris » et la belle étude d'Isabelle Saint-Martin sur « la place des œuvres d'art dans les églises parisiennes après Vatican II ", suivies de près de 250 pages de monographies d'édifices, classés par arrondissements (avec une écrasante et très compréhensible domination des arrondissements à deux chiffres, presque seuls concernés par les constructions nouvelles).

3 Sans doute ce livre de référence n'est-il pas parfait. Paris intra muros recèle non seulement des paroissiales, mais aussi des chapelles régulières (étudiées en assez grand nombre), des chapelles de collèges (représentées par Saint-Michel de Picpus et l'étonnant «music-hall liturgique » du Lycée Franklin) et des chapelles d'hôpitaux. Is. Saint-Martin et ses collègues ont montré tout l'intérêt de ces dernières ( $D e$ l'ar(t)chitecture en milieu hospitalier), et on regrette de ne pas les retrouver autrement qu'avec l'oratoire de l'Hôpital Bretonneau. On aimerait aussi que Paris et ses églises prenne parfois plus de distance avec le discours de l'institution ecclésiale. Le soutien donné par les « Chantiers du cardinal » a concédé au directeur de cet organisme le droit de signer l'avant-propos, tandis que la préface est de la plume de Jean-Marie Duthilleul. Tous les régimes autoritaires ont leur architecte, le lustigérisme a eu le sien en la personne de Duthilleul : l'appeler à participer à un travail critique incluant ses propres réalisations n'était sans doute pas le meilleur moyen d'assurer la totale indépendance de la démarche. On fera la même remarque pour les vifs éloges régulièrement décernés à Jean-Marie Lustiger. Il serait prudent, d'un point de vue d'historien, d'attendre que l'histoire des années Lustiger soit écrite pour se prononcer. Elle ne l'est nullement et ne le sera sans doute pas de sitôt, puisque le diocèse de Paris reste aux mains des continuateurs directs du système lustigérien. Seules sont disponibles pour l'heure des considérations hagiographiques sans valeur scientifique, qui invitent à la suspension $\mathrm{du}$ jugement. Plus largement, les auteurs ne trouvent pas toujours la bonne distance par rapport aux grands récits de la réforme liturgique produits par l'appareil idéologique du catholicisme post-conciliaire : la thèse continuiste du "mouvement liturgique " franco-belge est admise sans réserves, comme est repris le discours courant, historiquement inexact, sur le passage au versus populum. Rien de tout cela n'est dirimant; les lecteurs avisés rectifieront d'eux-mêmes, comme on dit, et ils bénéficieront avec reconnaissance de la masse considérable des données rassemblées et de l'exceptionnelle iconographie mise à leur disposition.

On a beaucoup construit, dans le diocèse de Paris, tout au long du $\mathrm{xx}^{\mathrm{e}}$ siècle. Dans la continuité du siècle précédent (dont traitera Jean-Michel Leniaud dans un volume à venir), il s'est d'abord agi de fournir vite de vastes lieux de rassemblement à des quartiers en pleine croissance. Le souci esthétique n'était pas premier, au point que certaines églises ont été démolies après quelques décennies, comme Notre-Dame 
d'Espérance, rue de la Roquette, où l'édifice de 1997 remplace une construction de 1928 signée Julien Barbier. D’autres subsistent sans impressionner, comme la "nouvelle église » de Saint-Honoré d'Eylau, avenue Poincaré, en brique et fonte. La hâte et la difficulté de rassembler les fonds nécessaires expliquent la qualité médiocre de certaines réalisations : si l'on examine par exemple les mosaïques livrées par la très prolifique maison Mauméjean à Sainte-Anne de la Butte-aux-Cailles, elles se révèlent inférieures à bien des chantiers provinciaux du même atelier, ou à l'impressionnant ensemble coloré et lumineux de Saint-Jean-Bosco ( $\mathrm{xx}^{\mathrm{e}}$ arrondissement).

5 Le vent tourne dans les années 1920-1930, à la fois parce que la culture artistique des autorités ecclésiastiques est meilleure et parce que les créateurs se font plus inventifs, dans la logique parfaitement indiquée par Isabelle Saint-Martin dans son Art chrétien/ art sacré. Sont ouverts alors des chantiers d'un intérêt exceptionnel, à commencer par celui du Saint-Esprit, avenue Daumesnil, suivi de bout en bout par Paul Tournon qui utilise le béton pour élever un grand édifice à coupole centrale que l'on n'a pas qualifié pour rien de "Sixtine $\mathrm{du} \mathrm{xx}^{\mathrm{e}}$ siècle». Derrière Maurice Denis, les meilleurs représentants de l'art sacré moderne s'emploient à y narrer en mosaïques et peintures murales largement brossées les progrès du christianisme depuis la Pentecôte, faisant de cette église un véritable musée qui n'a d'égal que l'église de l'exposition coloniale de 1931, remontée à Épinay sous le vocable de Notre-Dame des Missions. Même ampleur, même monumentalité, dans les mêmes années, à Saint-Pierre de Chaillot, qui joue aussi sur le modèle romano-byzantin adapté au béton, avec les impressionnantes interventions de Bouchard et les fresques incisées d'Untersteller.

De l'autre côté de la guerre, arrive le temps de l'« enfouissement »- au sens propre, à Paris, puisque plusieurs églises sont pensées à ce moment comme souterraines ou semienterrées (Saint-Albert-le-Grand rue de la Glacière, Saint-Joseph des Épinettes dans le $\mathrm{XVII}^{\mathrm{e}}$ arrondissement, et surtout Saint-Bernard de Montparnasse, chapelle de gare et emblème d'un christianisme nomade qui n'a pas survécu à la normalisation wojtylienne). Les années qui suivent immédiatement Vatican II appellent aussi un réaménagement général des sanctuaires - non pour mettre en œuvre la "liturgie du concile", qui n'existe pas, mais pour faire prévaloir une conception nouvelle de l'espace cultuel qui a réussi le prodige de devenir normative sans être jamais canonisée. Il a parfois fallu s'y reprendre à plusieurs reprises pour trouver un équilibre satisfaisant entre monuments anciens et pratiques inédites, ainsi que le rappelle Isabelle RenaudChamska à l'exemple de Saint-Médard. Des solutions radicales ont été adoptées, comme à Saint-Ignace, rue de Sèvres, où une ellipse liturgique occupe perpendiculairement la nef d'une très classique église néo-gothique (même principe à Saint-François de Molitor). Il est toutefois un cas plus significatif encore, qui est celui de la cathédrale métropolitaine. Il faudra bien écrire un jour une histoire contemporaine de NotreDame, qui n'était certes pas l'objet de ce volume, mais que la fonction de vaisseau amiral pour le diocèse rend indispensable à la compréhension de tous les autres chantiers. Des photos de "l'état Lustiger » laissent ici mesurer combien un examen de "l'état Marty » serait instructif.

7 Jean-Marie Lustiger, maître de l'Église parisienne de 1981 à 2005, restera comme un évêque bâtisseur: une dizaine d'églises, à un moment où l'on pouvait penser que le parc était définitivement constitué. Ces sanctuaires, disent les auteurs, « revendiquent leur identité », traduisent un "retour de visibilité ». Le "catholicisme ostensible " défini par Danièle Hervieu-Léger s'inscrit dans l'espace, revendiquant un dialogue un 
peu biaisé avec les aventures formelles de la modernité avancée, dont l'apothéose est peut-être Notre-Dame de l'Arche d'Alliance ( $\mathrm{xv}^{\mathrm{e}}$ arrondissement). Comme le relève très justement Isabelle Saint-Martin, la lecture de la croix dépourvue de poutre horizontale à Notre-Dame d'Espérance "suppose une certaine virtuosité spirituelle »... Plus immédiat est l'accès au retable de Keith Haring à Saint-Eustache, mais que dit vraiment ce « coup » des rapports entre art et foi à l'âge nucléaire ? Les plus récentes des églises de Paris sont-elles ouvertes à la quête indécise du «troisième homme » ou au contraire destinées surtout aux élites cléricales d'un temps de reconquête institutionnelle? Autant d'exemples des réflexions que fait surgir à chaque page un gros livre d'une étonnante richesse, indispensable à quiconque s'intéresse à l'histoire culturelle du christianisme contemporain. 